\title{
Threshold effects in catchment storm response and the occurrence and magnitude of flood events: implications for flood frequency
}

\author{
D. I. Kusumastuti ${ }^{1}$, I. Struthers ${ }^{1}$, M. Sivapalan ${ }^{2, *}$, and D. A. Reynolds ${ }^{1}$ \\ ${ }^{1}$ School of Environmental Systems Engineering, The University of Western Australia, 35 Stirling Highway, Crawley, Western \\ Australia, 6009, Australia \\ ${ }^{2}$ Centre for Water Research, The University of Western Australia, 35 Stirling Highway, Crawley, Western Australia, 6009, \\ Australia \\ *now at: Departments of Geography \& Civil and Environmental Engineering, University of Illinois at Urbana-Champaign, \\ 220 Davenport Hall, 607 S. Matthews Avenue, Urbana, Illinois 61801, USA
}

Received: 11 September 2006 - Published in Hydrol. Earth Syst. Sci. Discuss.: 23 October 2006

Revised: 26 June 2007 - Accepted: 16 August 2007 - Published: 20 August 2007

\begin{abstract}
The aim of this paper is to illustrate the effects of selected catchment storage thresholds upon runoff behaviour, and specifically their impact upon flood frequency. The analysis is carried out with the use of a stochastic rainfall model, incorporating rainfall variability at intra-event, interevent and seasonal timescales, as well as infrequent summer tropical cyclones, coupled with deterministic rainfall-runoff models that incorporate runoff generation by both saturation excess and subsurface stormflow mechanisms. Changing runoff generation mechanisms (i.e. from subsurface flow to surface runoff) associated with a given threshold (i.e. saturation storage capacity) is shown to be manifested in the flood frequency curve as a break in slope. It is observed that the inclusion of infrequent summer storm events increases the temporal frequency occurrence and magnitude of surface runoff events, in this way contributing to steeper flood frequency curves, and an additional break in the slope of the flood frequency curve. The results of this study highlight the importance of thresholds on flood frequency, and provide insights into the complex interactions between rainfall variability and threshold nonlinearities in the rainfall-runoff process, which are shown to have a significant impact on the resulting flood frequency curves.
\end{abstract}

\section{Introduction}

The flood frequency curve, typically estimated from observed flood records and widely used in flood estimation practice, is the culmination of complex interactions between climatic inputs (rainfall intensities, evaporation demand) and those landscape properties that have a bearing on the rain-

Correspondence to: D. I. Kusumastuti

(kusumast@gmail.com) fall to runoff to flood peak transformation, presented within a stochastic framework (Eagleson, 1972; Wood, 1976; Sivapalan et al., 1990; Sivapalan et al., 2005). For a given storm event, apart from its dependence on rainfall intensity and volume, the flood peak is a function of storm duration and the response time of the dominant flood producing process (Robinson et al., 1997a; Gupta and Waymire, 1998). However, time scales of subsurface flow and evapotranspiration, and longer time scales associated with rainfall, e.g., seasonality, are also important since together they determine the antecedent flow and soil moisture conditions in the catchment through the memory of previous, even distant, storm events via the catchment's water balance (Jothityangkoon et al., 2001).

Rainfall intensity exhibits temporal variability at a range of timescales, such as within-storm, between-storm, seasonal (annual), inter-annual and inter-decadal variabilities. Similarly, the catchment runoff response is associated with processes such as overland flow, subsurface flow and baseflow which also operate at a range of different time scales, associated with the various pathways that water takes to the catchment outlet and hence different travel distances and travel speeds. Thus the magnitudes of flood peaks and the shape of the flood frequency curve reflect, and are affected by, interactions between rainfall and runoff variabilities over the multiplicity of time scales (Robinson and Sivapalan, 1997b; Jothityangkoon et al., 2001).

A number of previous studies (Robinson and Sivapalan, 1997b; Blöschl and Sivapalan, 1997; Sivapalan et al., 2005) have explicitly incorporated the effects of within-storm patterns of rainfall intensity on flood peaks within the context of derived flood frequency analysis. A linear rainfall-runoff model was used in the flood studies carried out by Robinson and Sivapalan (1997a, b) and Sivapalan et al. (2005), which showed that the inclusion of within-storm patterns

Published by Copernicus Publications on behalf of the European Geosciences Union. 
contributed to a steepening of the flood frequency curves. This behaviour suggested that the nonlinearity of the interactions between temporal rainfall patterns and runoff processes may be significant, but such behaviour was not investigated further. Within the framework of a linear rainfallrunoff model, Sivapalan et al. (2005) quantified the effects of within-storm patterns in terms of a correction factor, which was shown to be a function of the ratio of the mean storm duration to the mean residence time of the catchment.

In general, runoff generation and flooding are nonlinear, threshold-driven processes. Saturation excess runoff occurs when the soil becomes saturated through the exceedance of an antecedent soil moisture deficit, and the ongoing rainfall rate exceeds the rate of ongoing subsurface flow and/or drainage. Even subsurface stormflow has been found to be a nonlinear, threshold driven process caused by the effects of subsurface heterogeneity (e.g., bedrock topography, preferred pathways etc.) (Spence and Woo, 2003). The role of threshold nonlinearities in surface and subsurface hydrology has become an intense area of research in recent years. For example, Blöschl and Sivapalan (1997) showed that the coefficient of variation (CV) of the flood frequency curve increased by a factor of 4 when nonlinearity is introduced into the rainfall-runoff relationship, effectively swamping the effects of the complex interactions of rainfall-runoff time scales mentioned previously. In more recent work, Fiorentino and Iacobellis (1999) have analysed the effect of runoff thresholds that underpin different generation mechanisms on the resulting flood frequency distributions.

This study has been motivated by specific flooding problems in the downstream of the Lake Warden catchment, located near Esperance, Western Australia, where the presence within the catchment of a large number of "finger lakes" of various sizes introduces obvious thresholds to the rainfallrunoff transformation, which are suspected to have a significant impact on the triggering of floods and on the shape of the flood frequency curve (Kusumastuti et al., 2005; Spence and Woo, 2006). In two instances over the past decade, environmentally destructive flood events have occurred in this region from the combination of paired high volume rainfall events, where the devastating flooding occurred only during the second, significantly smaller magnitude rainfall event. Those specific flooding events in Esperance represent clear evidence of the role of catchment thresholds, which can be defined as those catchment features which variously impart a threshold effect on the rainfall-runoff transformation.

In spite of the practical importance of catchment thresholds, which is well recognized by engineering hydrologists involved in flood estimation (Chow et al., 1998; Institution of Engineers Australia, 1987), the effects of catchment thresholds have received little attention in derived flood frequency analysis. Struthers and Sivapalan (2007) presented a theoretical framework to describe climate and catchment process controls upon flood frequency generally (i.e., not for a specific climate), including the role of spatial and temporal vari- ability and associated threshold nonlinearities in altering the flood frequency behaviour. Through this analysis, they identified important non-dimensional parameter groupings that can be used to characterise flood frequency response, under thresholds, in a general manner. The present study, however, is motivated by the specific problems of flooding in Lake Warden catchment near Esperance, Western Australia. However, owing to the lack of long time series data in this catchment, the present study remains predominantly an exploratory one, carried out in a hypothetical catchment but utilizing typical climate and catchment parameters that are representative of the Lake Warden catchment. The primary purpose of this study is a first order investigation into the effect of catchment storage thresholds, their interactions with nonlinear rainfall-runoff processes, and their combined impacts on flood frequency. With this in mind the model being used is a simple one, just sufficient to capture the main thresholds that impact on flood frequency - the results need to be interpreted in this light. The specific role of threshold effects caused by the finger-lakes themselves, over and above the effects of catchment storage thresholds, is the subject of a subsequent investigation (Kusumastuti et al., 2005). A Monte Carlo simulation based derived flood frequency approach (Eagleson, 1972; Ott and Linsley, 1972) is adopted, utilizing a synthetic realization of rainfall time series combined with simple but nonlinear conceptual rainfall-runoff models. The overall scientific objective is to gain insights into the roles of threshold nonlinearities on catchment storm response, their impact on the temporal frequency of occurrence and magnitude of the resulting flood peaks, and consequently on the flood frequency curve. Given the specific occurrence of flooding events in the Lake Warden catchment during the occurrence of summer storms under dry conditions, an additional objective is to understand the dominant process controls of intermittent flood events during summer storm events associated with infrequent tropical cyclones, and their impact on flood frequency.

The paper begins with descriptions of the stochastic rainfall model which was used to generate the synthetic rainfall time series and the four rainfall-runoff models used in the simulation of runoff time series. The rainfall-runoff models used vary systematically from a simple linear bucket without thresholds to a non-linear bucket with multiple storage thresholds. By comparing runoff generation behaviour for each model over a range of different climate and catchment parameterisations, the impact of thresholds upon the time series of runoff generation and flooding events and upon flood frequency could be examined. The implications of these results are then examined for flood estimation practice and approaches to future monitoring aimed at prevention and amelioration of catastrophic floods that may occur in the study region. 


\section{Methodology}

\subsection{Rainfall model}

The study used the stochastic rainfall generation model of Sivandran (2002), which is an extension of the model of Robinson and Sivapalan (1997b). This model accounts for seasonal variability in the dominant storm type by considering separate synoptic components (year-round) and a cyclonic component in summer months. The synoptic component considers each year to consist of 12 months, with storm durations and inter-storm periods estimated from observed rainfall data, while the summer cyclonic component assumes each year to consist of just 3 months, with a different set of storm durations and inter-storm periods reflecting the infrequent tropical cyclones. These two sequences are then superimposed, by concatenation, to obtain a complete rainfall time series.

\subsubsection{Synoptic rainfall model}

The model is capable of generating synthetic realizations of rainfall time series consisting of discrete rainfall events whose arrival times, durations, average rainfall intensity and within-storm intensity patterns are all random governed by specified probability density functions (pdf). Storm duration and inter-storm period are both considered to be exponentially-distributed, although with seasonally-varying mean values:

$f_{\tau_{r}}\left(t_{r} \mid \delta\right)=\frac{1}{\delta} \exp \left(-\frac{t_{r}}{\delta}\right) \quad t_{r}>0$

$f_{\tau_{b}}\left(t_{b} \mid \gamma\right)=\frac{1}{\gamma} \exp \left(-\frac{t_{b}}{\gamma}\right) \quad t_{b}>0$

where $\delta$ is the mean storm duration, and $\gamma$ is the mean interstorm period. These mean values are considered to vary deterministically with time of year according to the following sinusoids:

$\delta=\delta_{r}+\alpha_{r} \cos \left\{\frac{2 \pi}{\omega}\left(\tau-\tau_{r}\right)\right\}$

$\gamma=\gamma_{b}-\alpha_{b} \cos \left\{\frac{2 \pi}{\omega}\left(\tau-\tau_{b}\right)\right\}$

where $\delta_{r}$ and $\gamma_{b}$ are the seasonally averaged storm duration and inter-storm period, respectively, $\tau_{r}$ and $\tau_{b}$ are seasonal phase shifts which are assumed to be equal, $\alpha_{r}$ and $\alpha_{b}$ are the amplitudes of the seasonal variations of $t_{r}$ and $t_{b}$, respectively, $\tau$ is the time of year, and $\omega$ is the total number of time units in a year (i.e., $\omega=8760 \mathrm{~h}$ ).

The mean storm intensity $i$ is a random variable stochastically dependent upon storm duration $t_{r}$; that is, $i$ and $t_{r}$ follow the joint pdf, $f_{I, T_{r}}\left(i, t_{r} \mid \delta\right)$, which is also seasonally varying due to the variation of $\delta$. Correlation between $i$ and $t_{r}$ is expressed as:

$E\left[i \mid t_{r}\right]=a_{1} t_{r}^{b_{1}} \quad C V^{2}\left[i \mid t_{r}\right]=a_{2} t_{r}^{b_{2}}$

with the coefficient $a_{1}$ assumed to also vary seasonally in order to account for variability of rainfall generating mechanisms within the year:

$a_{1}=a_{1 m}+a_{1 a} \cos \left\{\frac{2 \pi}{\omega}\left(\tau-\tau_{a}\right)\right\}$

The power functions given in Eq. (5) provide relationships between $t_{r}$ and the first two moments of $f_{I}\left(i \mid t_{r}\right)$, the conditional distribution of $i$ given $t_{r}$, which is assumed to follow the gamma distribution:

$f_{I}\left(i \mid t_{r}\right)=\frac{\lambda}{\Gamma(\kappa)}(\lambda i)^{\kappa-1} \exp (-\lambda i)$

Both $\lambda$ and $\kappa$ are gamma distribution parameters and are functions of storm duration $t_{r}$. These parameters can be expressed, in terms of $t_{r}$ and the coefficients of the conditional statistics:

$\kappa=\frac{t_{r}^{-b_{2}}}{a_{2}}$ and $\lambda=\frac{t_{r}^{-b_{1}-b_{2}}}{a_{1} a_{2}}$

The mean storm intensity is further disaggregated to hourly intensity patterns (within-storm pattern) using stochastically generated mass curves (Huff, 1967). The temporal pattern generated by the stochastic rainfall model is highly dependent upon the random variables $w$, which governs how the total depth of rainfall within the event is disaggregated sequentially until the required temporal resolution of event rainfall is achieved. The random variables are drawn from a beta distribution that is given by:

$f_{w}(w)=\frac{1}{B\left(\eta_{1} \eta_{2}\right)} w^{\eta_{1}-1}(1-w)^{\eta_{2}-1}$

The selection of $\eta_{1}$ and $\eta_{2}$ is significant, as it is the magnitude of these parameters that controls the patterns of variability of rainfall within the event around the median. For the purposes of this study it is assumed that $\eta_{1}=\eta_{2}$; this results in a normalised mass curve which is symmetrical about $w=0.5$. The higher the values for $\eta$, the more the values tend to be centred on $w=0.5$. However if small values are used the resulting random variables drawn tend to be distributed at the extremes with $w$ values approaching zero or one. The values of $\eta$ used in this study are $0.5,1.5$, and 3 . This choice of the $\eta$ values is based on the analysis of within storm patterns of several years of storm data in the study region (Hipsey et al., 2002; Robinson et al., 1997b). Figure 1 presents typical rainfall hyetographs generated by the model for different values of $\eta$. The average intensity, and hence the total rainfall volume, is the same in all three cases. The simulated patterns demonstrate that lower $\eta$ values produce highly variable, even intermittent rainfall patterns, whereas higher $\eta$ values generate less variable rainfall, approaching almost uniform rainfall intensities. 

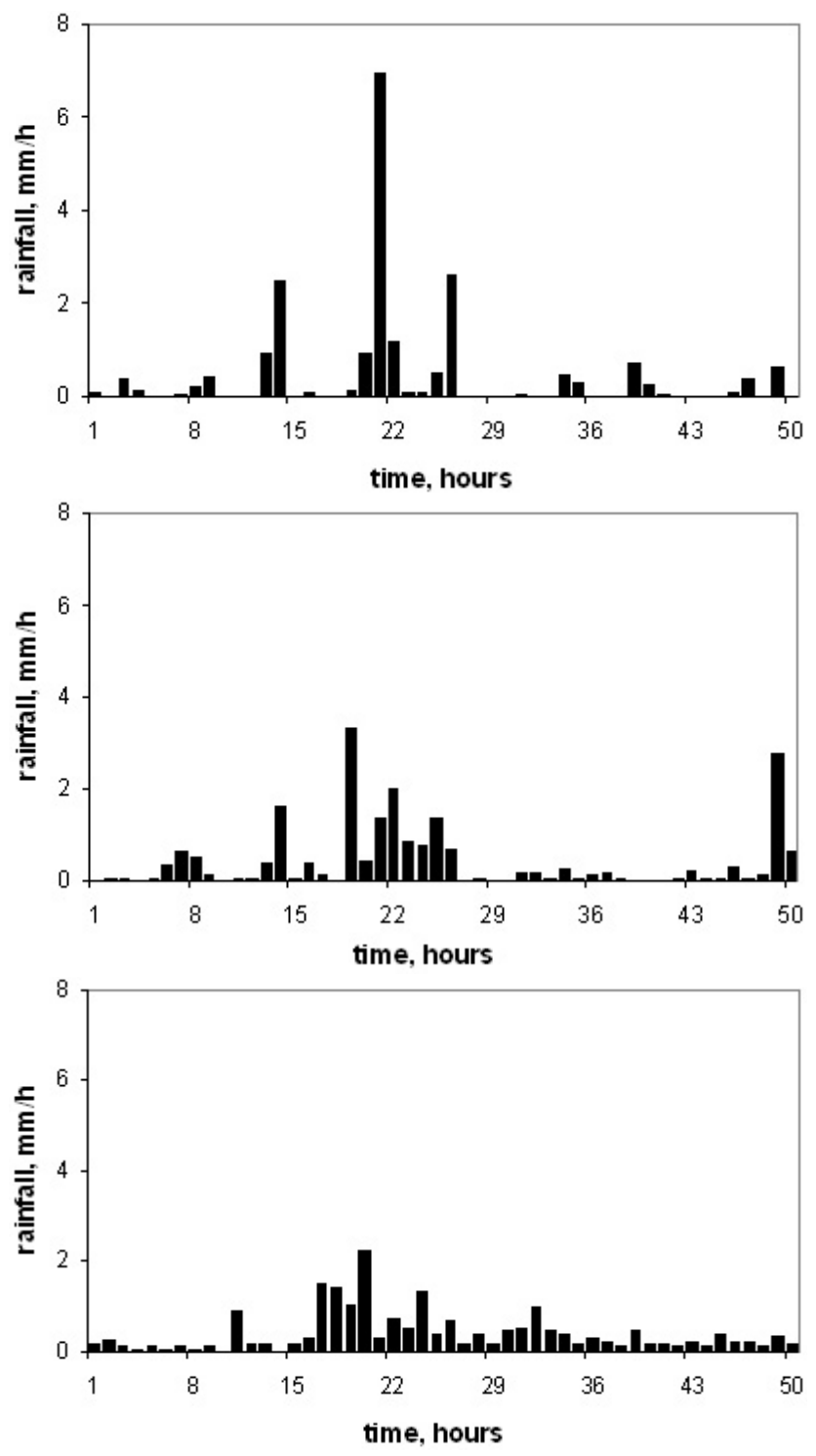

Fig. 1. The variability of individual storms in the rainfall time series for (a) $\eta=0.5$, (b) $\eta=1.5$ and (c) $\eta=3.0$.

\subsubsection{Cyclonic summer rainfall model}

A particular feature of rainfall that is crucial in the study region is the inclusion of the effects of large, infrequent but important tropical cyclones that tend to occur during the summer months of December, January and February. The town of Esperance experienced severe summer storms in January 1999 and again in February-March 2000. A total of 209 mm of rainfall was recorded in the January 1999 event, the heaviest rainfall event in the region since rainfall records began in 1889, and the resultant environmentally catastrophic flood was estimated to have a return period of around 200 years.

The same modelling framework outlined for synoptic rain-
Table 1. Rainfall Model parameters.

\begin{tabular}{lllll}
\hline \multirow{2}{*}{ Parameter } & Equation & \multicolumn{2}{c}{ Value } & Units \\
\cline { 3 - 4 } & & $\begin{array}{l}\text { Synoptic } \\
\text { rainfall } \\
\text { model }\end{array}$ & $\begin{array}{l}\text { Cyclonic } \\
\text { summer } \\
\text { rainfall model }\end{array}$ & \\
\hline$\delta_{r}$ & $(3)$ & 11 & 24 & hours \\
$\alpha_{r}$ & $(3)$ & 4.4 & 0 & hours \\
$\gamma_{b}$ & $(4)$ & 100 & 16800 & hours \\
$\alpha_{b}$ & $(4)$ & 69 & 0 & hours \\
$\tau_{r}=\tau_{b}$ & $(3),(4)$ & 0 & 0 & month \\
$\omega$ & $(3),(4)$ & 8760 & 2160 & hours \\
$a_{1}$ & $(6)$ & - & 2.4 & - \\
$a_{1 m}$ & $(6)$ & 0.40 & 0 & - \\
$a_{1 a}$ & $(6)$ & -0.30 & 0 & - \\
$b_{1}$ & $(5)$ & 0.08 & 0.08 & - \\
$a_{2}$ & $(5)$ & 3.4 & 2.0 & - \\
$b_{2}$ & $(5)$ & -0.55 & -1.5 & \\
\hline
\end{tabular}

fall (Sect. 2.1.1) was used in the cyclonic summer rainfall model. Several alterations were made in order to account for the different characteristics of cyclonic events. The summer cyclonic storm model generates a stochastic time series of 90 days duration representative of December, January and February, which was accomplished by setting parameter $\omega$ to $2160 \mathrm{~h}$ (Eqs. 3, 4 and 6). An equal probability of occurrence was applied to each summer month. The seasonal component of the stochastic rainfall model was removed as tropical storm arrivals appeared to totally random showing little preference for any of the three summer months. Therefore the amplitude of seasonal variations of storm duration $\alpha_{r}$ (Eq. 3), inter-storm period $\alpha_{b}$ (Eq. 4) and mean intensity $a_{1 a}$ (Eq. 6) were all set to zero. From the analysis of rainfall records in the region the temporal frequency of cyclonic rainfall events appeared to be, on average, once in 7-8 years, the inter-storm parameter $\gamma_{b}$ (Eq. 4) was therefore set as 700 days or 16800 hours (i.e., roughly 8 times 90 days). Table 1 presents the rainfall model parameterisations both for synoptic and cyclonic storms, which is based upon observed rainfall records for the Esperance region.

\subsection{Rainfall-runoff models}

Following Farmer et al. (2003), four models describing the most common hydrological processes in a catchment were utilized in this work, ranging from a simple linear bucket (Model 1) to a relatively more complex nonlinear bucket with thresholds (Model 4) as illustrated in Fig. 2. Model 1 is a very simple conceptualisation of the hydrological processes within a catchment, which transforms the rainfall input into runoff simply as a function of precipitation, storage and evaporation. Potential evaporation data is obtained from 
measured pan evaporation from Esperance Meteorological Bureau. The range of measured annual potential evaporation values is between $1500 \mathrm{~mm}$ to $2000 \mathrm{~mm}$. The runoff models developed in this paper used a fixed value of annual potential evaporation, equal to the mean annual potential evaporation of approximately $1700 \mathrm{~mm}$. The governing equations for the processes represented in Model 1 are:

$\frac{d S}{d t}=i(t)-E_{p}(t)-Q(t)$

$Q(t)=\frac{S(t)}{t_{c}}$

where $S$ is storage in mm, $t$ is time in hours, $Q$ is runoff in $\mathrm{mm} / \mathrm{h}$, and $t_{c}$ is the catchment response time (hours).

Model 2 expands upon Model 1 by adding a field capacity threshold, $S_{f c}$, such that flow will occur only if the storage exceeds this threshold. Field capacity is a commonly-used conceptual threshold, representing the water content below which capillary forces are larger than those of gravity, such that drainage and runoff are negligible. Model 2 has the same equation for describing storage change with time (Eq. 10) as Model 1, but uses a different equation for $Q(t)$.

$Q(t)=\frac{\left(S(t)-S_{f c}\right)}{t_{c}}$

where $S_{f c}$ is the field capacity threshold in $\mathrm{mm}$.

Model 3 introduces a bucket capacity, $S_{b}(\mathrm{~mm})$, such that runoff is now separated into two components: subsurface flow, $Q_{s s}(\mathrm{~mm} / \mathrm{h})$, when catchment storage exceeds the field capacity threshold; and saturation excess runoff or surface runoff $\left(Q_{s e}, \mathrm{~mm} / \mathrm{h}\right)$ when the bucket capacity is exceeded (Fig. 2). In view of the climate and soils in this region, the main runoff generating mechanism is subsurface stormflow, whereas infiltration excess runoff and deep groundwater flow are rare phenomena. For that reason, these two runoff components are not included in the model. The governing equation for the processes represented in Model 3 is:

$$
\frac{d S}{d t}=i(t)-Q_{s s}(t)-Q_{s e}(t)-E_{b s}(t)-E_{v e g}(t)
$$

In order to account for the effects of heterogeneity of vegetation cover, total evaporation is divided into bare soil evaporation $\left(E_{b s}\right)$ and transpiration $\left(E_{\mathrm{veg}}\right)$. The evaporation term in Model 3, $E_{p}(t)$ in $\mathrm{mm}$, is separated into evaporation from vegetation or transpiration, $E_{\mathrm{veg}}$ in $\mathrm{mm}$ and bare soil evaporation $E_{b s}$ in $\mathrm{mm}$. Transpiration is a function of the percentage of vegetation covering the catchment, $M$, and potential evaporation, $E_{p}$. The introduction of $E_{b s}$ and $E_{v e g}$ to replace $E_{p}$ in Models 3 and 4 is to provide continuity with previous modeling studies (e.g., Farmer et al., 2003). The model structure presented here worked well for many catchments in this region.

$E_{\mathrm{veg}}=M E_{p}$ if $S(t) \geq S_{f c}$

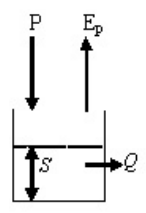

Model 1

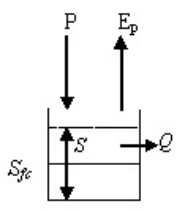

Model 2

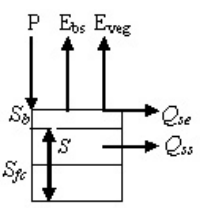

Model 3

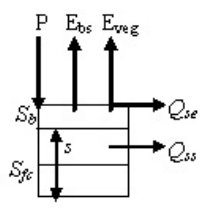

Model 4
Fig. 2. Bucket configurations for Models 1, 2, 3 and 4. The difference between Models 3 and 4 is the nonlinearity of Qss in Model 4 (Eq. 20).

$E_{\mathrm{veg}}=M E_{p}\left(\frac{S(t)}{S_{f c}}\right)$ if $S(t)<S_{f c}$

Bare soil evaporation is a function of potential evaporation and the portion of the catchment covered by vegetation.

$E_{b s}=E_{p}(1-M)$ if $S(t) \geq S_{b}$

$E_{b s}=E_{p}(1-M)\left(\frac{S(t)}{S_{b}}\right)$ if $S(t)<S_{b}$

Total runoff from the catchment is the summation of subsurface flow and surface runoff. Subsurface flow $\left(Q_{s s}\right)$ is a linear function of storage above field capacity and concentration time $t_{c}$.

$Q_{s s}=\left\{\begin{array}{c}\left(\frac{S(t)-S_{f c}}{t_{c}}\right) S_{f c}<S(t)<S_{b} \\ \left(\frac{S_{b}-S_{f c}}{t_{c}}\right) \quad S(t)>S_{b}\end{array}\right.$

Surface runoff $\left(Q_{s e}\right)$ occurs if the soil is fully saturated which occurs when the storage exceeds the bucket capacity $\left(S_{b}\right)$.

$Q_{s e}=S(t)-S_{b}$ if $S(t)>S_{b}$

The bucket capacity, $S_{b}$, is assumed to be equal to $S_{b}=\phi \mathrm{D}$, where $\phi$ is the catchment-average soil porosity and $D$ is the catchment-average soil depth. Bucket capacity, $S_{b}$, was calculated based on the estimated average depth of the upper layer of the duplex soils in the Lake Warden Catchment, multiplied by the porosity of the soil. The field capacity threshold $S_{f c}$ is on the product of the catchment-average field capacity, $f_{c}$, and $D$.

Model 4 is similar to Model 3, but with a non-linear storage-discharge relationship for subsurface flow. The linear storage-discharge relationship (Eq. 18) with single parameter $t_{c}$, is thus replaced with two parameters $a$ and $b$. The $a$ and $b$ values used in this study are normally estimated through recession analysis carried out on the measured streamflow data.

$Q_{s s}=\left\{\begin{array}{c}\left(\frac{S(t)-S_{f c}}{a}\right)^{\frac{1}{b}} \quad S_{f c}<S(t)<S_{b} \\ \left(\frac{S_{b}-S_{f c}}{a}\right)^{\frac{1}{b}} \quad S(t)>S_{b}\end{array}\right.$

Parameters of the rainfall-runoff models for Model 1 to Model 4 are described in Table 2. 
Table 2. Rainfall-runoff model parameters.

\begin{tabular}{|c|c|c|c|c|c|}
\hline \multirow{2}{*}{ Parameters } & \multicolumn{4}{|c|}{ Normal value/Range/List } & \multirow{2}{*}{ Units } \\
\hline & Model 1 & Model 2 & Model 3 & Model 4 & \\
\hline \multicolumn{6}{|l|}{$\begin{array}{l}\text { Storage- } \\
\text { discharge } \\
\text { relationship }\end{array}$} \\
\hline$t_{c}$ & 100 & 100 & 100 & - & hour \\
\hline$a$ & - & - & - & 70 & $\mathrm{~mm}^{0.5} \mathrm{~h}^{0.5}$ \\
\hline $\begin{array}{l}b \\
\text { Soil properties }\end{array}$ & - & - & - & 0.5 & - \\
\hline$S_{b}$ & - & - & $\begin{array}{l}150 \\
300\end{array}$ & $50-400$ & $\mathrm{~mm}$ \\
\hline $\begin{array}{l}S_{f c} \\
\text { Vegetation }\end{array}$ & - & 45 & 45,90 & $15-120$ & $\mathrm{~mm}$ \\
\hline $\begin{array}{l}M \\
\text { Rainfall model } \\
\text { parameter : }\end{array}$ & - & - & 0.1 & 0.1 & - \\
\hline$\eta$ & $\begin{array}{l}0.5,1.5, \\
3\end{array}$ & $\begin{array}{l}0.5,1.5 \\
3\end{array}$ & $\begin{array}{l}0.5,1.5 \\
3\end{array}$ & $\begin{array}{l}0.5,1.5, \\
3\end{array}$ & - \\
\hline
\end{tabular}

\section{Results}

3.1 Schematic description of thresholds in catchment storm response

To illustrate the impacts of threshold nonlinearities, we will first compare time series runoff response for each of Models 1 to 4 schematically. Figure 3a shows typical rainfall inputs and Fig. $3 b$ the corresponding runoff generated by Models 1 and 2. In Model 1 the catchment is conceptualized with infinite storage and no threshold, and as a result runoff magnitude is determined by the rainfall volume, evaporation and catchment's response time.

The catchment storage capacity remains infinite in Model 2 , but a field capacity threshold is introduced. As a consequence, rain must first bring soil moisture to a basic level of wetness, $S_{f c}$, at which point excess water becomes available for runoff generation. Since subsurface flow is zero at field capacity, the reduction of storage to below field capacity is due to evaporative drying during the inter-storm period. Figure $3 \mathrm{~b}$ shows that the field capacity threshold enhances the intermittency, with not all storms generating a runoff response.

Model 3 gives the system a finite storage capacity which, if reached, is capable of generating saturation excess surface runoff. Figure $3 \mathrm{c}$ shows the storm events and corresponding runoff responses (subsurface flow, $Q_{s s}$, and surface runoff, $Q_{s e}$ ) generated by Model 3. Differing from the response time for subsurface runoff, surface runoff is assumed to be immediately transferred downstream (response time $\sim 0 \mathrm{~h}$ ). The occurrence of surface runoff is determined by the value of the bucket capacity.
Model 4 assumes a non-linear storage-discharge function for subsurface flow. The difference between a linear and nonlinear storage-discharge relationship for subsurface flow can be seen by comparing Models 3 and 4 (Fig. 4), where the two models show similar recession behaviour but different peak responses. During low flow, Model 3 produces a higher flood peak than Model 4. Conversely, during high flow, the flood peak produced by Model 3 is lower than that from Model 4. Previous work has examined the impact of the nonlinear storage-discharge relationship (Farmer et al., 2003) in Australian catchments similar to the Lake Warden scenario. Farmer et al. (2003) found an under prediction of the flow duration curve by using a linear parameter, and an improvement in the flow duration curve with the utilization of a nonlinear approach.

\subsubsection{Effects of bucket capacity}

Soil depth is an important controlling parameter in flood events given the fact that soil moisture storage excess is a direct contributor to flooding. To investigate the effect of soil depth on the runoff response, Model 4 with bucket capacities of $100 \mathrm{~mm}, 150 \mathrm{~mm}$, and $200 \mathrm{~mm}$ are used to generate runoff responses (surface runoff and subsurface flow). Figures $5 \mathrm{a}, \mathrm{b}$, and $\mathrm{c}$ show that soil depth significantly impacts the frequency of occurrence of saturation excess surface runoff, i.e. deeper soils require more rainfall to fill, such that surface runoff is less likely to occur. Even when a deep soil generates saturation excess, the volume of saturation excess will be less than for shallower soils. Larger soil depths are also capable of generating higher rates of subsurface flow prior to becoming saturated, such that the contribution of subsurface flow to total runoff will be larger for deeper soils. 

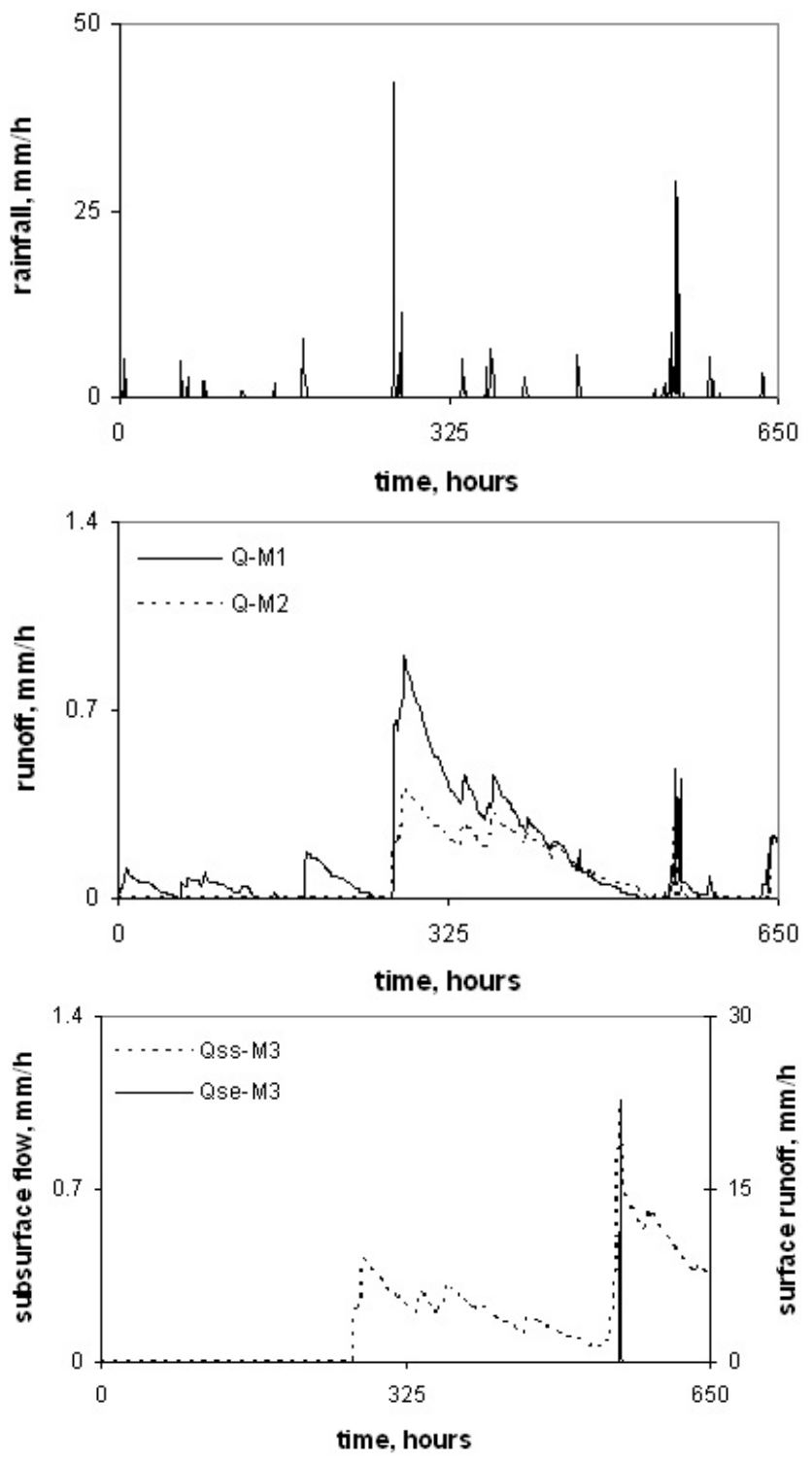

Fig. 3. Schematic representation of rainfall and corresponding runoff generated by Models 1, 2 and 3 (M1, M2, M3) using $\eta=0.5$.

\subsubsection{Effect of within storm pattern}

To investigate the impact of the degree of within-storm variability of rainfall intensity upon flood frequency, rainfall time series with three different values of $\eta$ were considered $(\eta=0.5,1.5$ and 3). Figure 6 illustrates the impact of each $\eta$ value upon subsurface flow and surface runoff. The figure shows that variation in $\eta$ significantly impacts the magnitude of surface runoff, but has a negligible impact upon subsurface flow. The impact of within-storm variability, which represents variability at small timescales, is most significant for a fast-response mechanism, such as surface runoff. In contrast, mechanisms with a large response, such as subsur-

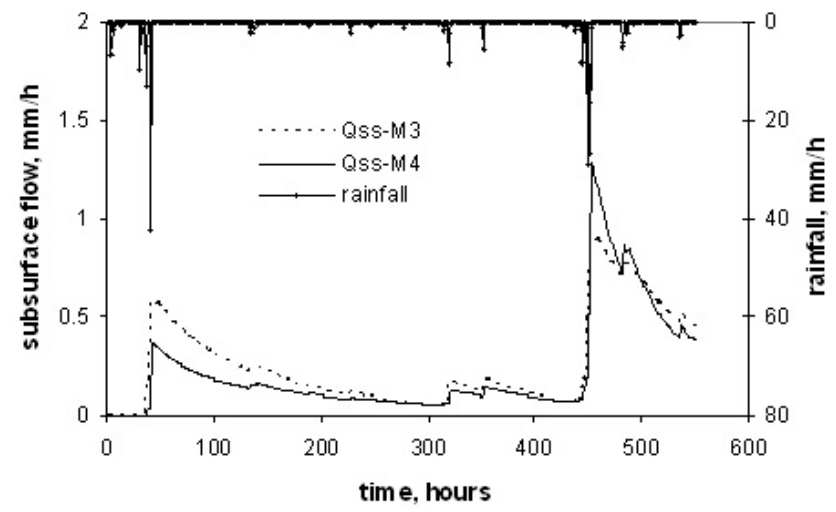

Fig. 4. Comparison between runoff responses generated by Models 3 and 4 (M3 and M4) using $S_{b}=300 \mathrm{~mm}$ and $\eta=0.5$.

face flow, will attenuate the small timescale variability. The magnitude of surface flow is determined primarily by the rate of the rainfall and the within-storm rainfall pattern. For the shallow soils of the Lake Warden Catchment, where surface runoff occurs frequently, within-storm variability will therefore have a significant impact upon flood response.

\subsection{Flood frequency for synoptic events}

The two most commonly used partial series for flood analysis are the annual exceedence series and annual maxima series (Chow et al., 1988). Annual exceedence series considers data above a predetermined threshold as extreme, with an advantage of selecting every significant flood present within the data series. The annual exceedence series consists of the $n$ largest flood peaks for a record of n-year duration. Annual maxima series, which is the most commonly used technique for flood frequency analysis in Australia (Pilgrim, 1987), selects the largest flood peak for each year of the data series and is the approach used in this study. There is a risk associated with using annual maximum series where often significant floods with respect to the entire data may be omitted because of another large flood in the same year. However, the use of sufficiently long time series may reduce these effects significantly, and that approach has been adopted in this study.

The flood frequency curves generated by all 4 Models incorporating the selected within-storm patterns are presented in Fig. 7. There is a significant difference in behaviour at low return periods as shown by the results generated by Models 1 and 2. In addition, the flood frequency curves for Model 2 remain slightly lower than those for Model 1, due to intermittent drying below field capacity.

The impact of the storage capacity threshold upon the flood frequency is manifested as a break in slope, associated with a change in flow mechanism from subsurface flow to saturation excess surface runoff, as shown by the flood frequency curves for Models 3 and 4. For example, Fig. 7a indicates that flood peaks associated with return periods of 

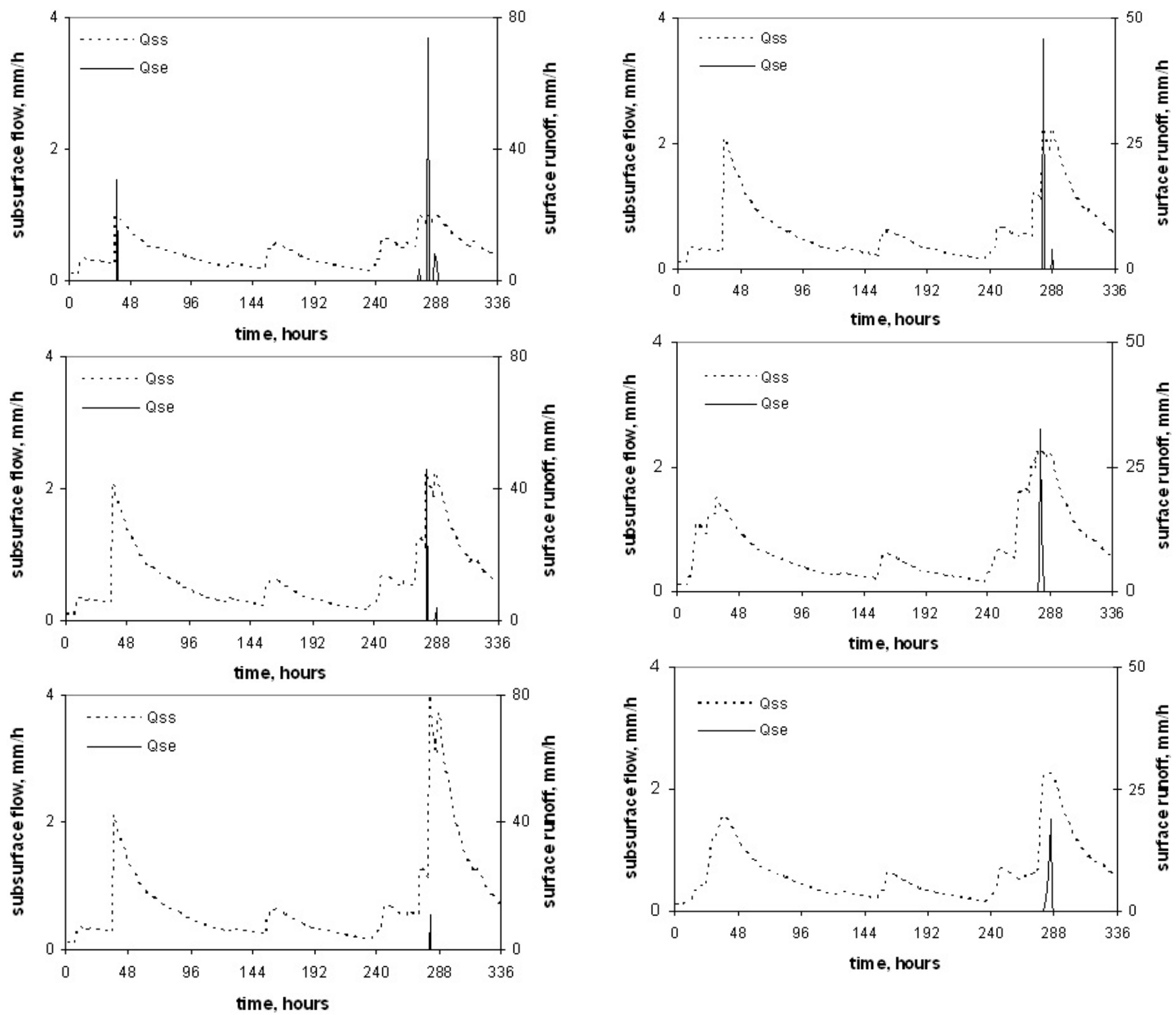

Fig. 5. The impact of bucket capacity generated by Model 4 using $\eta=0.5$ and (a) $S_{b}=100 \mathrm{~m}$, (b) $S_{b}=150 \mathrm{~mm}$, and (c) $S_{b}=200 \mathrm{~mm}$.

less than approximately 40 years are caused by subsurface flow only, whereas events with a larger return period have an additional surface runoff component. The flood frequency curves presented in Fig. 7 for Models 3 and 4 indicate a shift in position, which is due to the nature of the deterministic rainfall-runoff model, particularly the differences in the storage-discharge relationships used for subsurface flow.

Within-storm patterns have an observable impact upon the flood frequency curves for Models 3 and 4 only at return periods after the break in slope, where surface runoff is contributing to the flood peak (Figs. 7a, b, and c). Previous findings by Robinson and Sivapalan (1997b) and Sivapalan et al. (2005) for models without threshold nonlinearities estab-

Fig. 6. The impact of within storm patterns generated by Model 4 using $S_{b}=150 \mathrm{~mm}$ and (a) $\eta=0.5$, (b) $\eta=1.5$, and (c) $\eta=3$.

lished that higher degrees of within-storm variability lead to steeper flood frequency curves; the findings of this study clarify that such an impact is only important for the portion of the flood frequency curve associated with a fast runoff response mechanism, which is itself associated with the relative frequency of threshold exceedence. The flood peaks predicted with high within-storm variability $(\eta=0.5)$ reach $139 \mathrm{~mm} / \mathrm{h}$ for the 1000 year return period flood, significantly greater than the predicted flood peaks with medium $(\eta=1.5)$ and low $(\eta=3.0)$ variability.

As discussed previously, the bucket capacity (which represents soil depth), influences the relative frequency of activation of surface runoff. Based on observed soil properties in several locations in the catchment, bucket capacities 

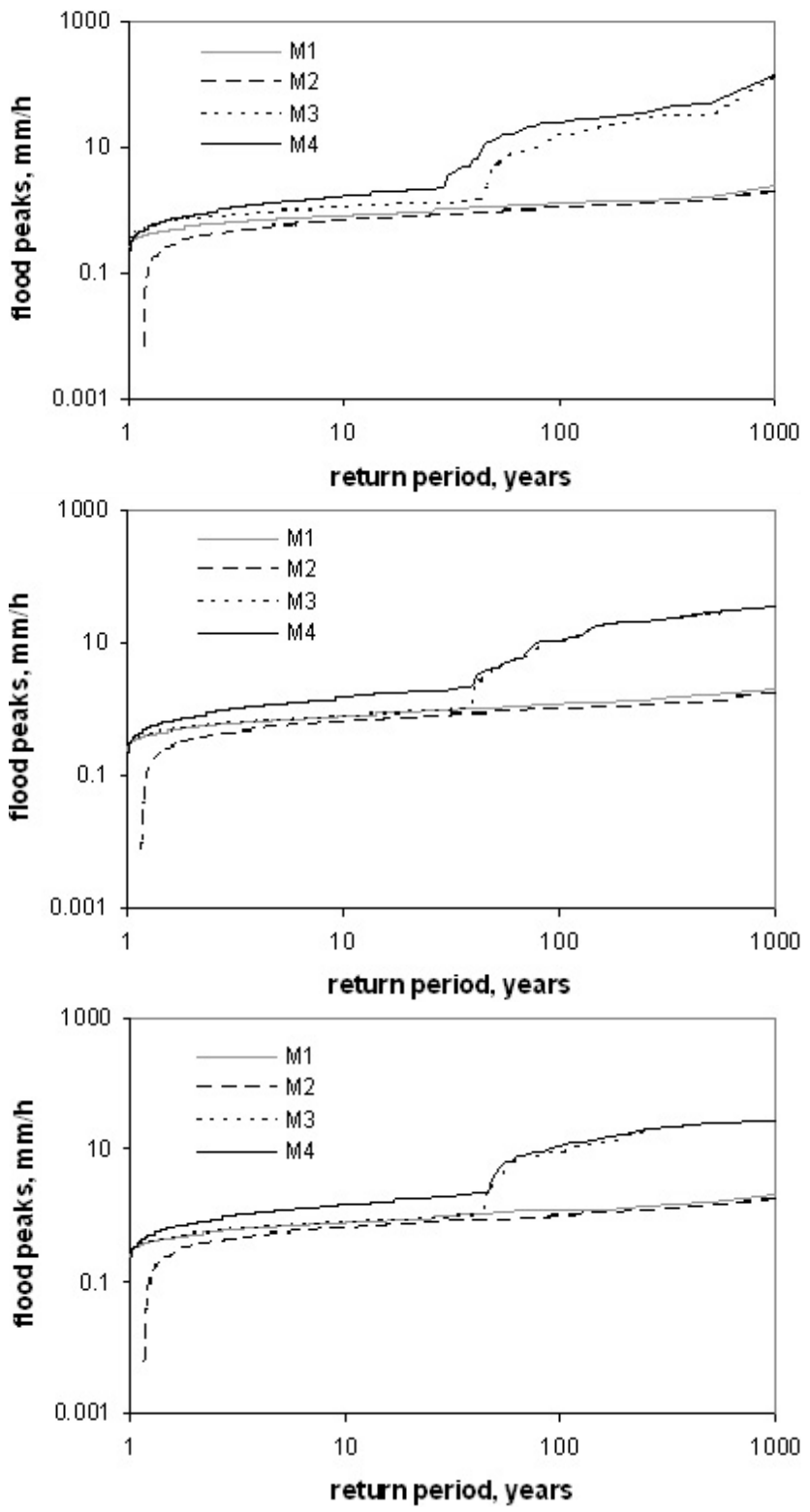

Fig. 7. Flood frequency curves for the four models using (a) $\eta=0.5$, (b) $\eta=1.5$, and (c) $\eta=3$, and $S_{b}=150 \mathrm{~mm}$.

of $100 \mathrm{~mm}$ to $400 \mathrm{~mm}$ were utilized to study the sensitivity of flood frequency to soil depth (Fig. 8). It is evident that the flood frequency curve for a bucket capacity of $100 \mathrm{~mm}$ has the earliest break compared to that for larger buckets (i.e. deeper soils). The inflection point in the response has moved from a return period of around 40 years to a return period of 500 years for a bucket capacity of $400 \mathrm{~mm}$. With the decreasing frequency of surface runoff, the impact of withinstorm variability upon flood frequency also decreases for deeper soils (results not shown here for reasons of brevity).

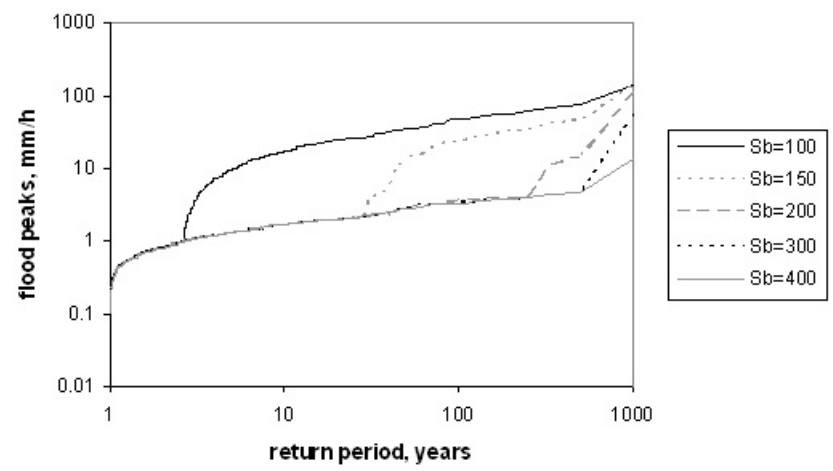

Fig. 8. Flood frequency curves generated by Model 4 using $\eta=0.5$ and various $S_{b}$.

\subsection{Runoff response of synoptic and cyclonic events}

A schematic representation of one year of storm events containing both synoptic and cyclonic storms and their corresponding flow components generated using Model 4 is presented in Fig. 9. A single summer cyclonic event occurs early in the year and synoptic events occur mostly between June and August (Fig. 9a). Saturation excess surface runoff occurs just twice within the year; once by a cyclonic storm and once by a synoptic event in winter (Fig. 9b). Subsurface flow responds to both cyclonic and synoptic events (Fig. 9c) The catchment storage fluctuates throughout the year with dry antecedent condition prior to the summer event and relatively high antecedent conditions during winter (Fig. 9d). The low antecedent condition of catchment storage during summer means that only a large-volume storm will be capable of triggering surface runoff, such as the presented summer event (Fig. 9a) which has a depth of $230 \mathrm{~mm}$ over 4 days. On the other hand, due to high antecedent conditions of catchment storage during winter, smaller storm depths are capable of triggering surface runoff.

A detailed examination of the occurrence of surface runoff and subsurface flow generated by synoptic events only, cyclonic events only, and by the combination of both is presented in Tables 3a and $b$. The frequency of occurrence for surface runoff caused by synoptic storm events is relatively low (Table 3a). The frequency of occurrence for surface runoff including summer cyclonic events is only slightly larger. Consideration of cyclonic events independently shows that slightly over 40 percent of cyclonic storm events are able to generate surface runoff in the shallowest bucket $(50 \mathrm{~mm})$; even though, numerically, the number of cyclonic events is negligible relative to the number of synoptic storms, they are much more likely than synoptic storms to trigger surface runoff, and therefore have a large potential to impact flood frequency. As the bucket capacity increases, the frequencies of surface runoff, due to both cyclonic and synoptic events, decreases. For sufficiently deep soils (e.g. $S_{b}=300 \mathrm{~mm}$ ), surface runoff triggering may be a summer phenomenon only. 

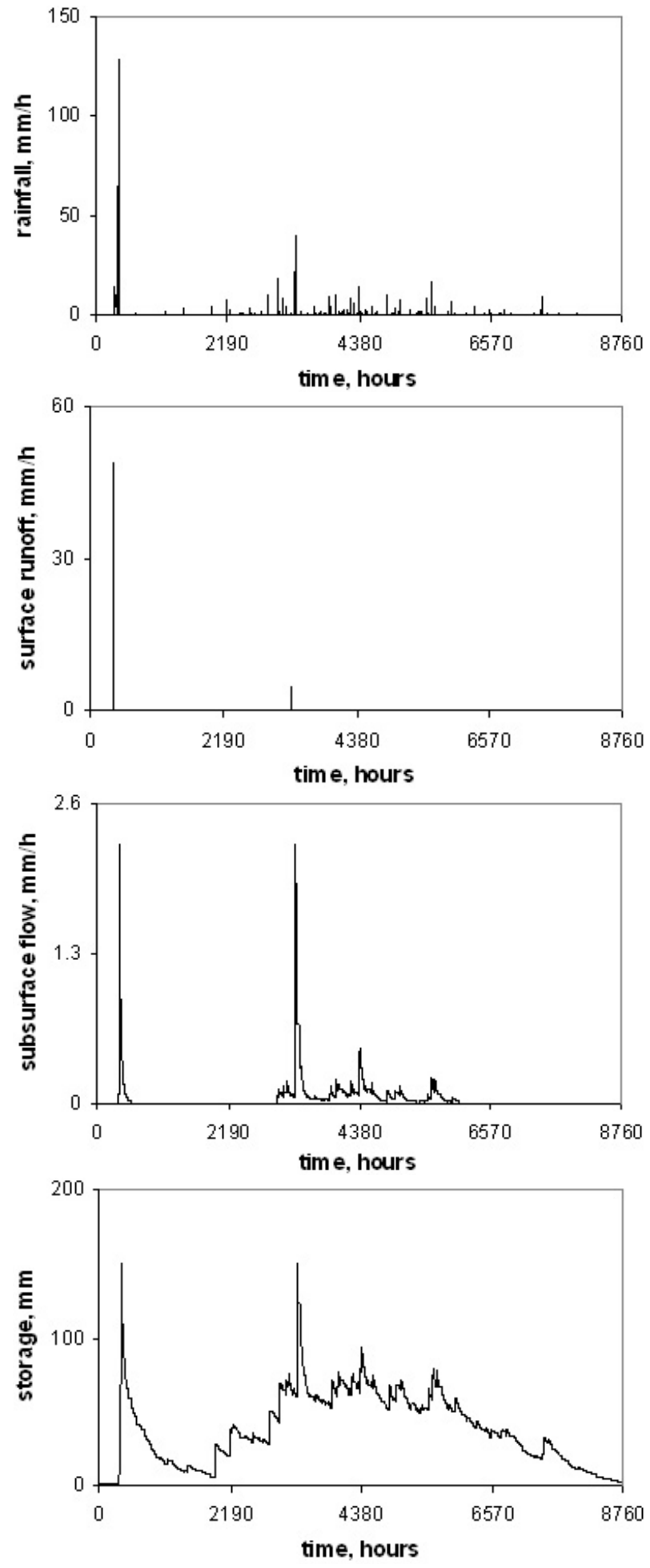

Fig. 9. Storm event and the corresponding flow components generated by Model 4 using $S_{b}=150 \mathrm{~mm}$ and $\eta=0.5$ in one year time window for (a) rainfall, (b) surface runoff, (c) subsurface flow, (d) catchment storage.
Table 3a. The frequency of occurrence for surface runoff.

\begin{tabular}{llll}
\hline \multirow{2}{*}{$S_{b}$} & \multicolumn{3}{c}{$f\left(Q_{s e}\right)$} \\
\cline { 2 - 4 } & Winter storm & $\begin{array}{l}\text { Winter \& } \\
\text { summer } \\
\text { storms }\end{array}$ & $\begin{array}{l}\text { Summer } \\
\text { storm }\end{array}$ \\
\hline 50 & 0.06910 & 0.06966 & 0.4037 \\
100 & 0.00529 & 0.00561 & 0.2110 \\
150 & 0.00035 & 0.00053 & 0.1193 \\
200 & 0.00004 & 0.00011 & 0.0551 \\
250 & 0.00001 & 0.00002 & 0.0092 \\
300 & 0.00000 & 0.00001 & 0.0092 \\
\hline
\end{tabular}

Table 3b. The frequency of occurrence for subsurface flow.

\begin{tabular}{llll}
\hline \multirow{2}{*}{$S_{b}$} & \multicolumn{3}{c}{$f\left(Q_{s s}\right)$} \\
\cline { 2 - 4 } & Winter storm & $\begin{array}{l}\text { Winter \& } \\
\text { summer } \\
\text { storms }\end{array}$ & $\begin{array}{l}\text { Summer } \\
\text { storm }\end{array}$ \\
\hline 50 & 0.758 & 0.760 & 0.734 \\
100 & 0.740 & 0.742 & 0.642 \\
150 & 0.726 & 0.729 & 0.578 \\
200 & 0.714 & 0.718 & 0.560 \\
250 & 0.705 & 0.710 & 0.541 \\
300 & 0.698 & 0.702 & 0.523 \\
\hline
\end{tabular}

The frequency of subsurface flow occurrence generated by synoptic events is relatively much higher (i.e. 70\%; Table 3b). A larger soil depth slightly reduces the occurrence of subsurface flow, indicating threshold effects, as the field capacity threshold may increase with deeper soil depth. The frequency of occurrence of subsurface flow generated by cyclonic storm events only is more than $70 \%$ at the shallowest bucket capacity $\left(S_{b}=50 \mathrm{~mm}\right)$, but decreases considerably with deeper bucket capacity. The decrease of the frequency of subsurface flow occurrence due to the increase of field capacity threshold as the bucket capacity increases will increase the ability for evaporation to cause drying below field capacity.

\subsection{Analysis of flood frequency curves including cyclonic} events

An examination of the flood frequency of the individual flow components (i.e. subsurface flow and surface runoff) generated by Model 4 for synoptic events only, and for synoptic and cyclonic events combined, is presented in Fig. 10. The figure indicates that the addition of summer cyclonic storms significantly increases flood magnitudes, by more than an order of magnitude relative to the synoptic-only case. The inclusion of summer cyclonic events also increases the 

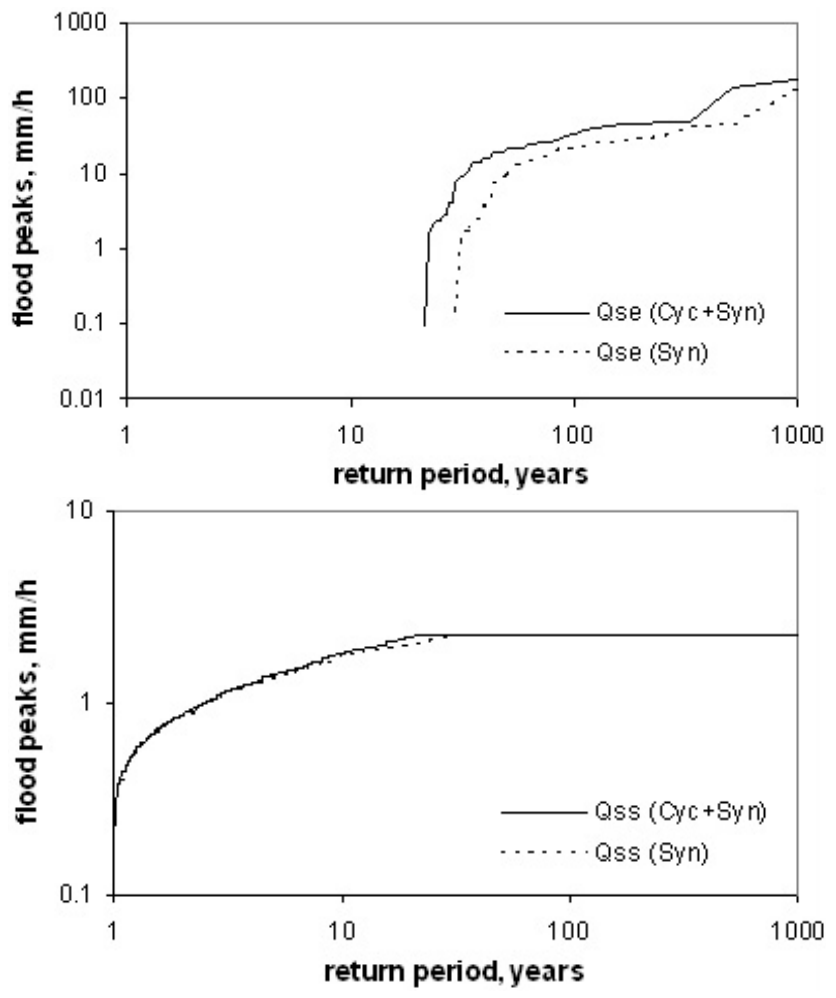

Fig. 10. Flood frequency curves for (a) surface runoff and (b) subsurface flow generated by synoptic events only (Syn) and synoptic and cyclonic events (Cyc+Syn) using Model 4 with $S_{b}=150 \mathrm{~mm}$ and $\eta=0.5$.

frequency of surface runoff, resulting in a break of slope at lower return periods in the flood frequency curve. The inclusion of cyclonic storms increases the frequency of surface runoff triggering directly, as suggested in Table $3 \mathrm{a}$, as well as indirectly by increasing antecedent soil moisture leading up to the synoptic rainfall peak in winter. Interestingly, the flood frequency curve due to subsurface flow only is not significantly impacted by the inclusion of cyclonic events (Fig. 10b), with the only difference being a slight decrease in the value of the return period at which the subsurface flow reaches its maximum value (i.e. the saturated value of subsurface flow, as given by equation 20 when $S(t)>S_{b}$.

The flood frequency responses for the complete (cyclonic and synoptic) rainfall model and for the synoptic events only are shown for Model 1 (Fig. 11a) and Model 4 (Fig. 11b) for both low and high within-storm variability. For the linear model (Model 1) the magnitude of the 1000-year flood peak is approximately halved if cyclonic events are not incorporated. This is a direct result of the larger storm depth due to cyclonic event at high return period. The impact of within storm pattern variability is insignificant (Fig. 11a) even at high return period of the flood frequency, as the runoff generated by Model 1 represents subsurface flow which has large concentration time.
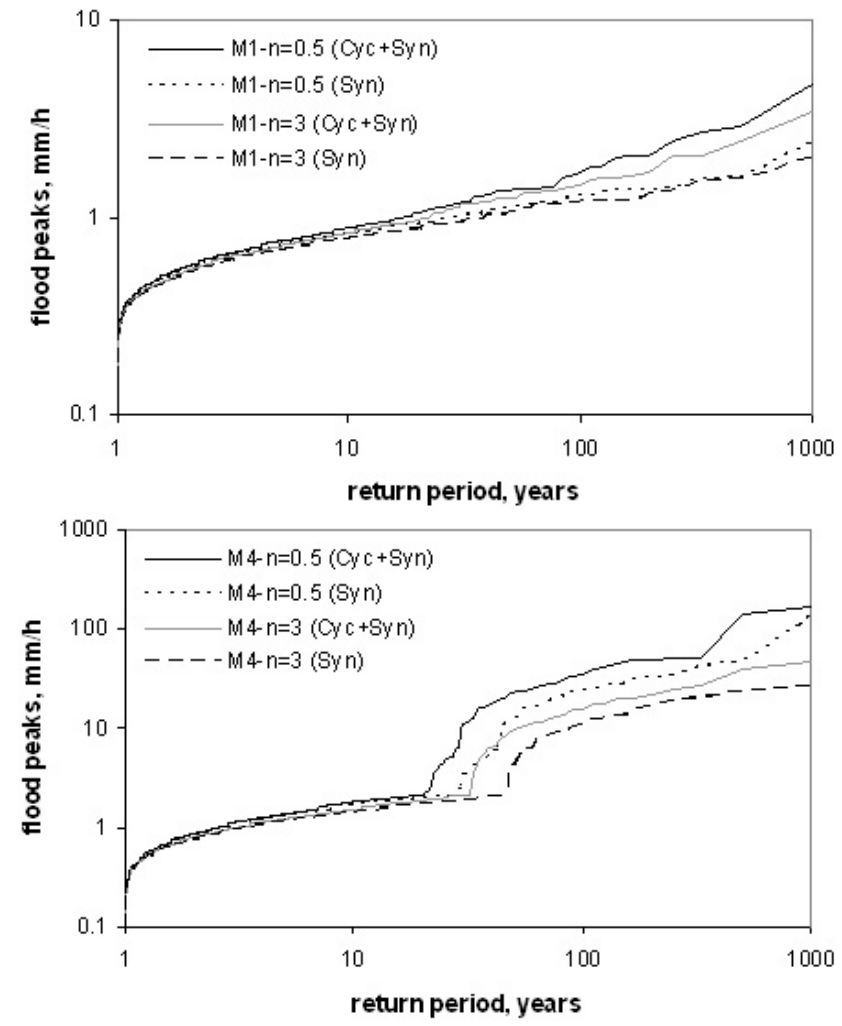

Fig. 11. Flood frequency curves generated by (a) Model 1 and (b) Model 4 using synoptic events only (Syn) and synoptic and cyclonic events (Cyc+Syn) for $S_{b}=150 \mathrm{~mm}, \eta=0.5$ and $\eta=3$.

Figure $11 \mathrm{~b}$ clearly shows that the inclusion of cyclonic storm events using high within storm variability $(\eta=0.5)$ impact on an additional inflection point occurring at high return periods of the flood frequency response generated by Model 4. Given that the flood frequency curve for the low within-storm variability case does not exhibit this secondary inflection point, it suggests that the combination of large cyclonic storm depths combined with strong within-storm variability can lead to rare, extreme magnitude flood responses (Fig. 11b).

The flood frequency responses generated by Model 4 for the cyclonic events, and for the synoptic events independently, are presented in Figs. 12a and b. In addition, the impact of bucket capacities on the flood frequency response for each event is examined. The flood frequency curves generated by synoptic events show the response on the impact of bucket capacity, such that the flood frequency curve for a bucket capacity of $150 \mathrm{~mm}$ has an early break compared to that using $S_{b}=300 \mathrm{~mm}$. Figures $12 \mathrm{a}$ and b show that the flood frequency curves generated by summer cyclonic events curtail at return period of $\sim 40$ years, due to the requirement of a minimum storm volume which is required to overcome the field capacity and soil depth thresholds present due to the dry antecedent conditions prevalent in summer. 

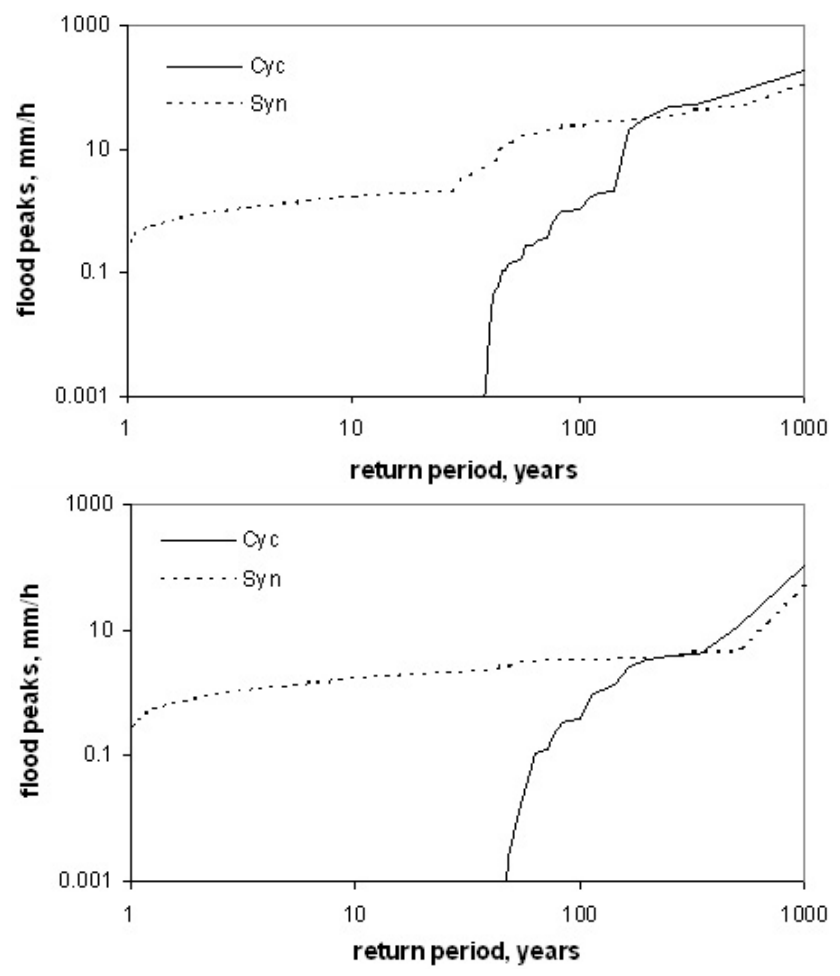

Fig. 12. Flood frequency curves generated by Model 4 using $\eta=0.5$ and (a) $S_{b}=150 \mathrm{~mm}$ and (b) $S_{b}=300 \mathrm{~mm}$ by synoptic storm only (Syn) compared to cyclonic summer storm only (Cyc).

\section{Discussion and conclusions}

The paper has investigated the effect of catchment thresholds upon flood frequency. The catchment thresholds that were examined include field capacity storage and a total storage capacity. For the parameterisation of climate and landscape used in this study, which relate to a specific catchment in Western Australia, model results suggest that most storms trigger a subsurface flow response, with surface runoff due to saturation excess occurring relatively rarely.

Analysis of the effect of thresholds has been performed systematically in this study, by utilizing a range of simple to complex models which add a single threshold at a time. Thresholds cause nonlinearity in the rainfall-runoff transformation, where runoff response is not only nonlinearly dependent on the magnitude of rainfall inputs but also on the catchment thresholds. The field capacity threshold requires the rainfall to bring soil moisture to a basic level of wetness, the point where excess water will enable subsurface flow generation. The role of field capacity is clearly demonstrated in the results produced by Model 2 (as compared to Model 1 ), with the lack of occurrence of runoff at low return periods (Fig. 7, for Model 2) being due to the catchment storage falling below the field capacity threshold for the entire year as a result of low rainfall volume in those years relative to potential evaporation. For a given climate, the magnitude and frequency of occurrence of saturation excess, which is a threshold-activated process, are both inversely related to the magnitude of the catchment storage capacity, $S_{b}$; as this capacity increases, both the magnitude and frequency of threshold exceedence will decrease.

The derived flood frequency approach adopted in this work demonstrated the impact of thresholds, where the thresholds impart a significant change on the shape and magnitude of the flood frequency. A change in the dominant runoff generating mechanism associated with threshold exceedence is manifested as an inflection point in the flood frequency curve. The interactions between climatic inputs (rainfall intensities, evaporation demand, dryness index, seasonality and within storm pattern), landscape properties (soil depth, field capacity and concentration time) and soil moisture/antecedent condition (water balance), have been clearly demonstrated to control the rainfall to runoff response, and therefore impact the flood frequency curve. This complex interaction, although somewhat intuitive when its components are considered in isolation, can result in system behaviours that are not normally considered in the modelling of rainfall to runoff transformations, nor in the design of engineered flood control systems.

The study of the impact of summer cyclonic storm events on flood frequency was an additional aim of this work, given historical instances of summer flooding in the study catchment. The research indicated that summer storm characteristics and the interaction between winter rainfall and evaporation which affect the antecedent catchment conditions for summer storm events strongly impacts the occurrence and magnitude of the flood events. The difference of the catchment state between summer and winter storm events lies in the antecedent catchment wetness, where the antecedent condition is driven by seasonality of synoptic events and seasonality of evaporation. During winter months the rainfall rate exceeds the evaporation rate causing relatively wet antecedent conditions, and therefore small floods are frequent due to small to medium rainfall intensities. If large rainfall intensities occur during this period, the magnitude of the flood peak will be at the greatest. However, the largest rainfall intensities occur during summer months with relatively dry antecedent conditions, such that small floods are less frequent but a number of large floods have occurred. The flood frequency curves for synoptic (year-round) and cyclonic (summer-only) storm events show a continuous curve with the break demonstrating the change of mechanism and the largest flood peak at the highest return period is due to cyclonic summer events.

The study has some implications for our understanding of other types of catchment threshold behaviour, such as the overflow behaviour of small lakes within the Lake Warden catchment. In general, the storages of the lakes tend to increase during winter and almost dry during summer months. However, the flow contribution to the lakes following large 
volume summer cyclonic events may exceed lake storage capacity, causing overflow into the town and the wetlands system which is located downstream of the catchment, as has occurred in recent years. This is a major concern to the management of Lake Warden catchment and surrounding wetlands system. The Lake Warden wetlands system is an important landmark and resting place to many migratory water birds and rare flora species, and the system is listed in the "Ramsar List", (the Ramsar Convention is a list of wetlands of international importance formulated on the basis of ecological, botanical, zoological, limnological or hydrological criteria) (CALM, 1997). The quantification of the runoff during these events will assist the catchment and wetlands management.

However, the utilization of the method presented has its own limitations in that the results presented here only dealt with a hypothetical catchment and the model parameterisation is limited to the catchments which have similar climatic and catchment characteristics. Climatic and hydraulic data from the study catchment is also limited such that a validation of the model cannot be performed. Furthermore the rainfall-runoff model utilized in this study is simple and does not include a rate threshold, and the process that largely depends on the intensity of rainfall and related to infiltration excess runoff. Nevertheless, the model developed using long time series of synthetic rainfall data adapted to the catchment coupled with rainfall-runoff model including catchment thresholds can be used as a tool to predict and take precautionary measures to reduce the impact of the floods in the Lake Warden catchment.

Overall the study has provided valuable insights into the process controls of flood frequency which can be achieved through utilization of the derived flood frequency method. A better understanding of the mechanisms that trigger runoff, their frequency of activation, and magnitude of runoff response will improve the management capabilities of the Lake Warden catchment and other similar catchments in the region. The results are valuable for understanding the occurrence of subsurface flow and surface runoff, which is essential to assist in the mitigation of the flood response of both synoptic winter and cyclonic summer storm events.

Traditional statistical flood frequency analyses based on limited records of flood series do not recognize the underlying processes and change of dominant processes with increasing return period. In the presence of significant thresholds and climatic features such as infrequent summer flood events caused by tropical cyclones traditional techniques are fraught with considerable difficulties. Flood records that do not contain samples from these infrequent floods tend to over-estimate their return periods, whereas records that do contain samples from these summer floods tend to underestimate their return periods, as in both cases the flood frequency analysis is dominated by the more common winter floods. Derived flood frequency analysis procedures such as the one presented here can be extremely useful to as- sess the frequency of such extreme floods through a much more realistic assessment of the associated changes in process controls. They also focus attention on the conditions under which these extreme floods are caused, which enables managers and engineers to design monitoring schemes that can help predict or prevent such floods from ever occurring.

Acknowledgements. This work was financially supported by an AUSAID scholarship awarded to the first author and by an Australian Research Council (ARC) Linkage Project awarded jointly to the last two authors. This support is gratefully acknowledged. We thank T. Massenbauer and other staff of the Department of Conservation and Land Management (CALM) for their financial and institutional support. SESE research report SESE 046.

Edited by: C. Hinz

\section{References}

Blöschl, G. and Sivapalan, M.: Process controls on regional flood frequency: coefficient of variation and basin scale, Water Resour Res., 33(12), 2967-2980, 1997.

CALM (Department of Conservation and Land Management): Esperance Lakes Nature Reserves. Draft Management Plan for the National Parks and Nature Conservation Authority, Perth, Western Australia, 1997.

Chow, V. T., Maidment, D. R., and Mays, L. W.: Applied Hydrology, McGraw-Hill, New York, 1988.

Eagleson, P. S.: Dynamics of flood frequency, Water Resour. Res., 8(4), 878-898, 1972.

Farmer, D., Sivapalan, M., and Jothityangkoon, C.: Climate, soil, and vegetation controls upon the variability of water balance in temperate and semiarid landscapes: downward approach to water balance analysis, Water Resour Res, 39(2), 1035, doi:10.1029/2001 WR000328, 2003.

Fiorentino, M. and Iacobellis, V.: Non-linearity effects in the process of floods generation. Proc. EGS Plinius Conference on Mediterranean Storms, Maratea, Italy, 14-16 October 1999.

Gupta, V. K. and Waymire, E.: Scale variability and scale invariance in hydrological regionalization, pp. 88-135, in: Scale Invariance and Scale Dependence in Hydrology, edited by: Sposito, G., New York: Cambridge University Press, 1998.

Hipsey, M., Sivapalan, M., and Menabde, M.: The incorporation of risk in the design of engineered catchments for rural water supply in semi-arid Western Australia, Hydrol. Sci. J., 48(5), 709-727, 2003.

Huff, F. A.: Time distribution of rainfall in heavy storms, Water Resour. Res., 3(4), 1007-1018, 1967.

Pilgrim, D. H. (Ed.): Australia Rainfall and Runoff, The Institution of Engineers Australia, Barton, ACT, 1987.

Jothityangkoon, C. and Sivapalan, M.: Temporal scales of rainfallrunoff processes and spatial scaling of flood peaks: Space-time connection through catchment water balance, Adv. Water Resour., 24(9-10), 1015-1036, 2001.

Jothityangkoon, C. and Sivapalan, M.: Towards estimation of extreme floods: examination of the roles of runoff process changes and floodplain flows, J. Hydrol.. 281, 206-229, 2003. 
Kusumastuti, D. I., Reynolds, D., and Sivapalan, M.: Impact of the presence of a network of interconnected lakes within a catchment on flood frequency. Presented at the Seventh IAHS Scientific Assembly, Foz do Iguacu, Brazil, April 3-9, 2005.

Ott, R. F. and Linsley, R. K: Streamflow frequency using stochastically generated hourly rainfall, in: International Symposium on Uncertainties in Hydrologic and Water Resources Systems, 1, 230-244, Univ. of Ariz., Tucson, 1972.

Robinson, J. S. and Sivapalan, M: An investigation into the physical causes of scaling and heterogeneity of regional flood frequency, Water Resour. Res., 33(5), 1045-1059, 1997a.

Robinson, J. S. and Sivapalan, M.: Temporal scales and hydrological regimes: Implications for flood frequency scaling, Water Resour. Res., 33(12), 2981-2999, 1997b.

Sivandran, G.: Effect of Rising Water Tables and Climate Change on Annual and Monthly Flood Frequencies. B. Eng. Thesis, Centre for Water Res., Univ. of West. Aus., Crawley, Australia, 2002.

Short, R.: A conceptual hydrogeological model for the Lake Warden recovery catchments Esperance, Western Australia. Resource Management Technical Report 200, 2000.
Sivapalan, M., Wood, E. F., and Beven, K.: On hydrologic similarity: 3. A dimensionless flood frequency model using a generalized geomorphologic unit hydrograph and partial area runoff generation, Water Resour. Res., 26(1), 43-58, 1990.

Sivapalan, M., Blöschl, G., Merz, R., and Gutknecht, D.: Linking flood frequency to long-term water balance: Incorporating the effects of seasonality. Water Resour. Res., 41, W06012, doi:10.1029/2004WR003439, 2005.

Spence, C. and Woo, M.-K.: Hydrology of subarctic Canadian shield: soil filled valleys, J. Hydrol., 273, 151-166, 2003.

Spence, C. and Woo, M.-K.: Hydrology of subarctic Canadian Shield: heterogeneous headwater basins, J. Hydrol., 317, 138154, 2006.

Struthers, I. and Sivapalan, M.: Conceptual investigation of process controls upon flood frequency: role of thresholds, Hydrol. Earth Sys. Sci., 11, 1405-1416, 2007.

Wood, E. F.: An analysis of the effects of parameter uncertainty in deterministic hydrologic models, Water Resour. Res., 12(5), 925-932, 1976. 